\title{
Mechanical Size Effects in Miniaturized Lead-Free Solder Joints
}

\author{
PETER ZIMPRICH ${ }^{1,3}$ USMAN SAEED, ${ }^{2}$ AGNIESZKA BETZWAR-KOTAS, ${ }^{1}$ \\ BRIGITTE WEISS, ${ }^{1}$ and HERBERT IPSER ${ }^{2}$ \\ 1.-Faculty of Physics, University of Vienna, Strudlhofgasse 4, 1090 Vienna, Austria. \\ 2.-Department of Inorganic Chemistry-Materials Chemistry, University of Vienna, Währing- \\ erstrasse 42, 1090 Vienna, Austria. 3.—e-mail: peter.zimprich@univie.ac.at
}

Future reliability and quality control of microelectronics will greatly depend on a detailed understanding of the complex mechanical and thermal properties of miniaturized lead-free solder joints. Therefore, the question of the occurrence of size effects or dimensionally induced constraints, which could change the mechanical properties of solder joints in small dimensions dramatically, has become the focus of investigation. In this study we investigated the influence of decreasing gap size on the tensile, shear, and stress relaxation behavior of solder joints to investigate the occurrence of size effects and dimensionally induced constraints, which could change the mechanical properties of solder joints significantly in micrometer dimensions. Residual stresses might remain in the solder joints during high-temperature dwell in thermomechanical fatigue. Model solder joints $(\mathrm{Sn} 3.5 \mathrm{Ag} / \mathrm{Cu})$ of rectangular shape with gap sizes varying between $25 \mu \mathrm{m}$ and $850 \mu \mathrm{m}$ were prepared by reflow soldering to achieve near-industrial soldering processing. Scanning electron microscopy was used for analyzing the microstructure and the complex modes of fracture and crack propagation in the solder interconnect. The observed tensile behavior can be interpreted in terms of an existing theory for brazed joints to complement finite-element analysis that is usually used for a description of these phenomena.

Key words: Lead-free solder joints, mechanical size effects, mechanical constraints, tensile test, shear test, stress relaxation, reliability

\section{INTRODUCTION}

Due to environmental and health concerns, the use of traditional lead-based solders in electrical and electronic equipment has been restricted by legislation in various parts of the world. The necessary substitution by corresponding lead-free solder alloys gave rise to numerous scientific and technical investigations on the properties of solder joints created from these new materials. ${ }^{1}$

Investigations of the effect of specimen size on properties of the bulk solder materials have shown that bulk data can be used only if the size of the solder joint is larger than a certain representative volume, ${ }^{2}$ and traditional tensile testing is incapable

(Received March 19, 2007; accepted August 13, 2007; published online: October 23, 2007) of predicting the mechanical behavior of real solder joints in electronic packages. Thus available data on bulk materials are not reliable if one considers the extremely small solder volumes $\left(<10^{-12} \mathrm{~m}^{3}\right)$ in modern microelectronic devices. Several investigations have been conducted on the thermomechanical integrity and reliability of solder joints, also with respect to specimen size,${ }^{2-4}$ the influence of rather brittle intermetallic compounds (IMCs) (such as $\mathrm{Cu}_{3} \mathrm{Sn}$ and $\mathrm{Cu}_{6} \mathrm{Sn}_{5}$ ), on the strength ${ }^{5,6}$ or the tensile fracture of solder joints ${ }^{7}$ as well as deformation characteristics of solder joints during shear loading. ${ }^{8}$ Nevertheless, very few systematic experimental studies on the effect of the reduced solder size and geometry on the mechanical performance are available in the literature. ${ }^{9}$ The current investigation was performed in tensile and shear mode using rectangular-shaped specimen because of the simple geometry and easier physical interpretation of a 
principal constrained situation. Shear loading is of course the more-critical and more-important situation in real solder joints, but interpretation is not straightforward compared to tensile testing, therefore this investigation focused on the tensile behavior of constrained joints. The situation in real soldered joints as used in microelectronics is of course much more complex but, nevertheless, it can be assumed that constraining effects in tensile and shear loading will play an important role in the understanding of the mechanical behavior of interconnects.

For the development of the constitutive relationships needed for modeling the thermomechanical fatigue behavior of solder joints, better understanding of stress relaxation processes under constrained conditions is of great importance. ${ }^{10-12}$ When solder joints are subjected to thermal cycling during the operation of electronic systems, thermal strains are generated within the solder joint due to the coefficient of thermal expansion (CTE) mismatch between the solder and the substrate. The stress generated within the joint depends upon the value of the imposed thermal strain. Solder joints operate at high homologous temperatures (>0.65 $T_{\mathrm{m}}$ ) in the environment of electronic systems and could be subjected to thermal cycling from $-50^{\circ} \mathrm{C}$ to $150^{\circ} \mathrm{C}$ (or even more) with dwell periods at the temperature extremes. ${ }^{10}$ In order to assess the effect of dwell periods on the thermomechanical fatigue behavior of such solder joints, evaluation of the stress relaxation process is necessary.

\section{SIZE EFFECTS AND DIMENSIONAL CONSTRAINTS}

\section{The Approximation by Orowan for Mechanical Constraints Under Tensile Loading}

The principle of size effects on the mechanical behavior of materials was originally formulated by $\mathrm{Nix}^{13}$ and later addressed again by Arzt. ${ }^{14}$ They pointed out the microstructural or dimensional constraints due to the interaction of physical and dimensional parameters that have to be taken into account when the dimensions of a specimen become very small (micrometers or even smaller) and therefore the mechanical response to loading is changed. A typical example of this effect would be the interaction between the size of dislocation loops and a thin foil with a comparable thickness. Another type of dimensional constraint can be formulated in terms of the ratio of geometrical dimensions only, i.e., the thickness-to-gap ratio of model joints as investigated in this work.

The effects of these dimensional constraints on the tensile strength of solder joints have recently been discussed, and evidence was found that solders are highly constrained in the proximity of an interface with a stiffer material ${ }^{15,16}$ and that the plasticity of the solder is restricted. ${ }^{6}$ Simultaneously with our investigation ${ }^{17}$ experimental results were described by means of finite-element analysis (FEA), indicating an inverse relationship (using a power-law description) between the tensile strength and gap size. ${ }^{18}$ Although these efforts were very successful for the description of the specific specimen under investigation, it seems useful to reintroduce some of the pre-existing models into this discussion. There is a lack of description of the principle amount of the constraint effects occurring at the lower and upper boundaries related to the simple mechanical parameters of the base and solder material. Using these parameters, modeling could be useful to estimate the extent of constraint effects in addition to the experimental or simulation-based description of joint properties.

In 1971 Saxton, West, and Barret described the deformation characteristics of brazed joints under tension with different gap sizes, ${ }^{19-21}$ based on the approximations calculated by Orowan et al., ${ }^{22}$ and the same approach should also be valid for soldered joints. They showed that the joint strength should be independent of the yield strength of the base material as long as the latter is greater than the tensile strength of the brazed (or soldered) joint. The Orowan approximation predicts that the strength of the joint should be directly proportional to the yield strength of the braze (or solder) material.

The strength of a transverse brazed or soldered joint should depend on a geometrical factor $t / d$, where $t=$ thickness of the joint and $d=$ diameter (Fig. 1), according to Ref. 23. Orowan's theory for $\sigma_{\text {yield }}$ of the brazed (soldered) joint, which also defines the fracture strength $\sigma_{\mathrm{F}}$ of the joint if the

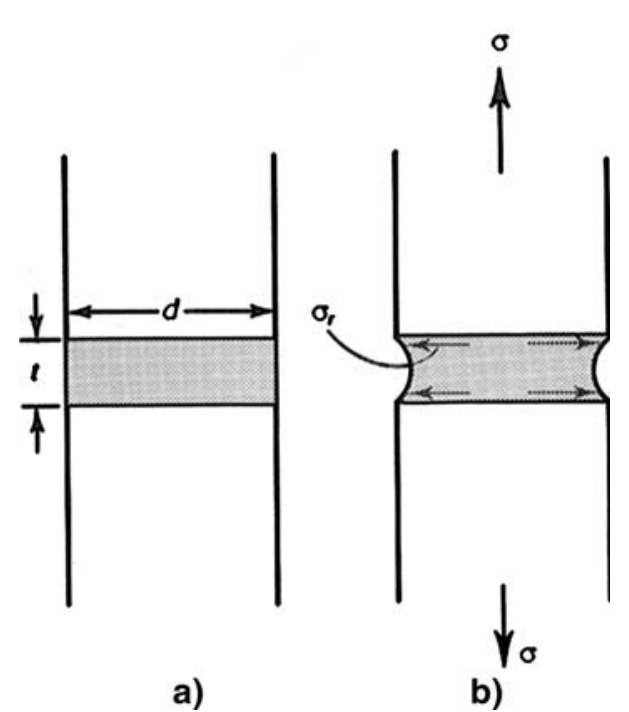

Fig. 1. (a) The geometry of brazed (soldered) joints is characterized by the ratio of the thickness $(t)$ to the diameter $(d)$. (b) When subjected to a tensile stress, the weaker braze (solder) is restrained from plastically deforming by the development of a secondary stress $\sigma_{r}$ at the braze/base metal interface. The lower $t / d$, the greater the ratio of $\sigma_{r}$ to $\sigma$ and the greater the flow resistance of the braze. ${ }^{23}$ 
braze (solder) material behaves like an ideal rigid plastic body, gives

$$
\sigma_{\mathrm{F}}(\text { joint })=\sigma_{\mathrm{UTS} / \text { yield }}(\text { braze or solder }) \times(1+d / 6 t) \text {. }
$$

The approximation therefore predicts a hyperbolic curve as the general shape of the fracture strength of the joint versus $t / d$. The upper and lower limits for the expected fracture strength $\sigma_{\mathrm{F}}$ (joint) of the joint can be determined by using the ultimate tensile strength $\sigma_{\mathrm{UTS}}$ or the yield strength $\sigma_{\text {yield }}$, respectively. Experimentally it was found that the UTS of the joint was the more-convenient experimental parameter to determine, because fracture strength for thick solder joints is not easy to define due to the stress-strain behavior of thick samples, which appear to be highly nonclassical in shape, showing high ductilities with a very prolonged development of fracture (see also Figs. 5 and 8). For thin joints, $\sigma_{\mathrm{F}}$ (joint) and $\sigma_{\mathrm{UTS}}($ joint $)$ appear to be almost identical because of high brittleness. Therefore $\sigma_{\mathrm{UTS}}($ joint) was determined experimentally, however, bearing in mind that Orowańs approximation was originally given for fracture strengths.

\section{The Influence of Intermetallic Compounds (IMC) on the Tensile Behavior of Solder Joints Under Constraint Conditions}

Brazed joints as investigated in Refs. 19-21 do not exhibit any IMC layers, therefore it was not clear whether the experimental results on fracture strain would be influenced by the presence of IMCs, as they are always present in solder joints. However, it was suggested that the formation of an IMC layer might reduce the interfacial bond strength. In this paper the lead-free solder was soldered directly to copper pads, i.e., the resulting intermetallic layer will be somewhat different from the one usually encountered in engineering practice. In most microelectronics applications an underbump metallization layer is used (e.g., $\mathrm{Ni}$ as a diffusion barrier and $\mathrm{Au}$ as a passivation layer) on top of the copper pad, which results in a different intermetallic layer after soldering. However, stress concentrations due to material discontinuities also have to be taken into account and microstructural effects must also be considered in a discussion of the deformation behavior of solder joints. Changes of microstructure as well as the influence of IMC thickness and properties in soldered joints will contribute to these constraint effects. It may be considered that for very thin samples $(\leq 10 \mu \mathrm{m})$ the influence of microstructure and IMCs should change this constraint behavior, due to the higher volume fraction of IMCs, smaller grains in the solder and therefore additional microstructural and dimensional size effects. ${ }^{24}$ However, as constraint effects are principle mechanical phenomena, the different nature of intermetallics will not influence the observed strengthening. The presence of intermetallic layers will somewhat complicate the situation in terms of strengthening behavior, but we want to point out that constraining effects result because of the specific properties of the base and solder materials, i.e., through the ratio of the UTS and yield strength, respectively.

\section{EXPERIMENTAL}

Based on this reasoning we concentrated our investigation on tensile, shear, and stress relaxation testing to assess the bonding strength of joints with varying gap sizes. The strain was measured by a noncontacting laser speckle extensometer with a gauge length of $15 \mathrm{~mm}$ across the solder joint. ${ }^{25,26}$ The actual strain of the solder joints was calculated considering the initial thickness of the solder gap. The model solder joints were manufactured from deformed electrolytic copper plates (99.9 wt.\%) with a length of $55 \mathrm{~mm}$ and a rectangular cross-sectional area $(10 \times 2 \mathrm{~mm})$. A Sn-3.5Ag alloy (in mass percentage), prepared from the pure elements, was used to solder the copper plates end to end. The specimens were fixed inside a sample holder, which allowed the gap size to be adjusted between $850 \mu \mathrm{m}$ and $25 \mu \mathrm{m}$. The soldering process itself was carried out applying a near-industrial reflow temperature profile for lead-free soldering in a commercial reflow furnace (Zelflow RO4, LPFK Laser \& Electronics AG, Germany). After soldering, the samples were dumb-bell shaped to achieve a solder joint with a soldered area of $3 \times 2 \mathrm{~mm}^{2}$ (Fig. 2a); they were polished and subsequently annealed at $80^{\circ} \mathrm{C}$ for $3 \mathrm{~h}$. To assess the bonding strength of the joints with varying gap sizes, tensile tests were performed at room temperature using a commercial $5 \mathrm{kN}$ tensile testing machine and a fixed cross head speed of $0.5 \mathrm{~mm} / \mathrm{min}$ for all tests. The results of tensile tests for each gap size were determined as the average from at least six specimens. The reproducibility of the data was found to be on the order of $10 \%$, as indicated in Fig. 4.

To investigate the influence of gap size on the shear strength of solder joints at $25^{\circ} \mathrm{C}$, single-lap shear specimens were prepared from deformed electrolytic copper plates (Fig. 2b) using the same annealing and polishing procedure as used for tensile and shear specimen. The soldered area of the joints was $4 \mathrm{~mm}^{2}$, which is higher than the soldered areas used in electronic systems (about $1 \mathrm{~mm}^{2}$ ); the higher area was found to achieve better joint reproducibility.

Stress relaxation experiments for $750,550,250$, and $150 \mu \mathrm{m}$ solder joints coupled with electrolytic copper as used for the tensile tests were carried out using a strain rate $1.2 \times 10^{-4} \mathrm{~s}^{-1}$. The tests were performed at $25^{\circ} \mathrm{C}$ (room temperature) and $120^{\circ} \mathrm{C}$. A hot-air furnace was used to heat the specimen and the specimen temperature was controlled within $\pm 1^{\circ} \mathrm{C}$. The relaxation results were determined from two specimens to confirm the reproducibility of the data. 
a) Gauge length $15 \mathrm{~mm}$

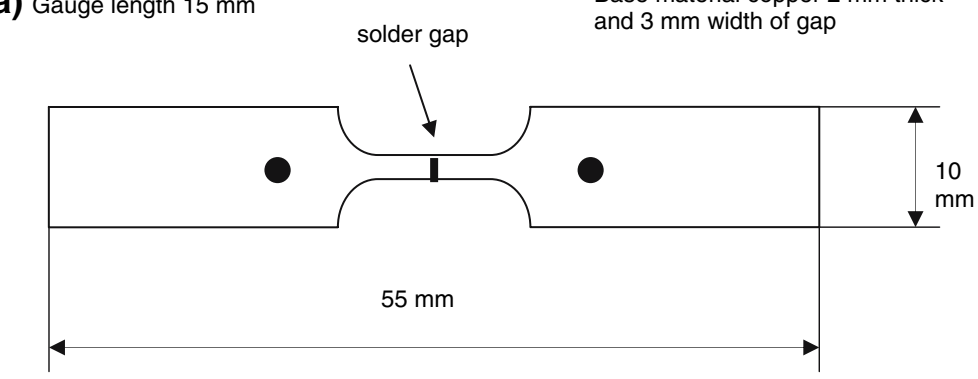

b)

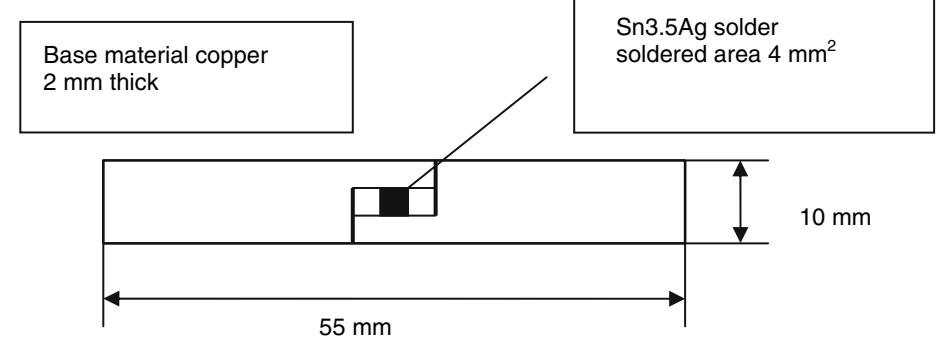

Fig. 2. (a) Schematic of the specimen geometry for the tensile and stress relaxation tests. The two dots (indicating the gauge length) are the locations of the laser points on the sample surface for the contactless strain measurements performed with the laser speckle extensometer. (b) Schematic of the specimen geometry for the shear tests (single-lap shear).

\section{RESULTS AND DISCUSSION}

\section{Tensile Response of Solder Joints}

For solder joints with decreasing gap sizes down to $25 \mu \mathrm{m}$ a very pronounced increase in tensile strength can be observed (Fig. 3), approaching that of the copper base material (for which a value of $300 \mathrm{MPa}$ had been determined experimentally). On the other hand, for a gap size of $850 \mu \mathrm{m}$ there is a clear trend towards the tensile strength of the solder material itself (experimentally determined to be $50 \mathrm{MPa}$ for the Sn-3.5Ag used, which is in good agreement with the literature value of $55 \mathrm{MPa}$, see also Ref. 27). Several stress-strain curves were determined for each gap size, and the results for the tensile strength and fracture strain are shown in Fig. 4. The typical microstructure of two different solder joints before loading is shown in Fig. 5. It can be seen that the microstructure is somewhat coarser for a larger solder gap. This change in microstructure might play an additional role in the development of increased strength for smaller solder joints because reduced grain sizes will lead to higher strength. It can be hypothesized that the tensile behavior will change significantly if the size of the gap becomes comparable to this mean grain size due to the microstructural or dimensional size effect, as discussed previously.

In Orowan's approximation the geometry of the tensile specimen was chosen to be cylindrical but our results showed a quite similar behavior for the rectangular-shaped samples (recalculated for a similar area) and the experimental curve lies between the calculated upper and lower limits, as demonstrated in Fig. 4, accompanied by a

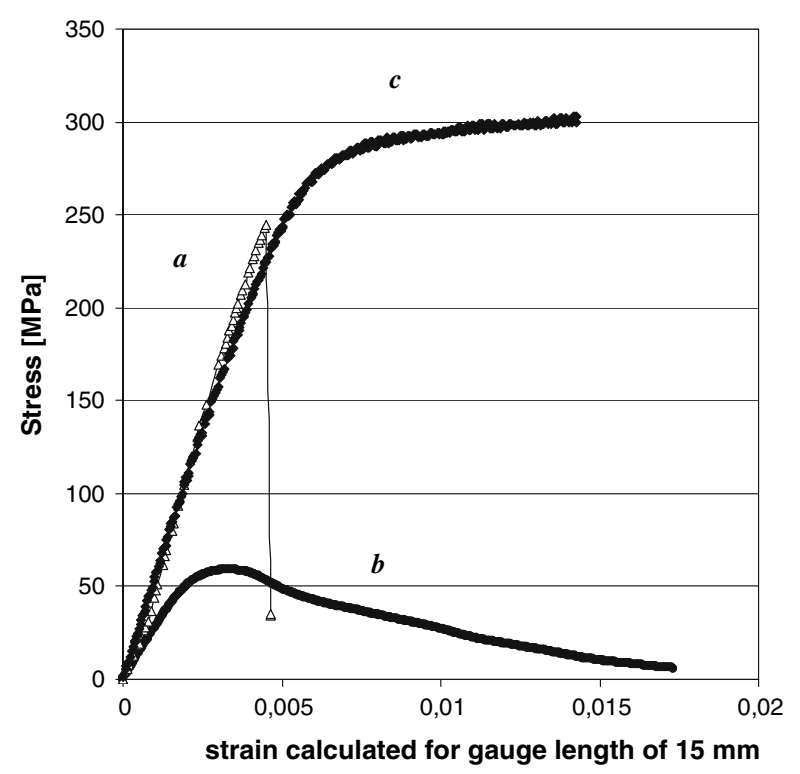

Fig. 3. Typical stress-strain curves of: (a) a thin joint $(25 \mu \mathrm{m}$ gap size) and (b) a thick joint ( $800 \mu \mathrm{m}$ gap size); a specimen of base material copper is shown for comparison (c).

significant decrease of fracture strain, which is usually not considered in the literature.

If the thickness of the solder joint reaches some critical (minimum) value, its properties will change completely: it cannot be assumed to be unconstrained at all and a complex three-dimensional stress distribution will develop. These effects in tensile as well as shear tests are the result of the boundary conditions. Usually this is to be avoided in materials testing (principle of Saint Vernant), but in 


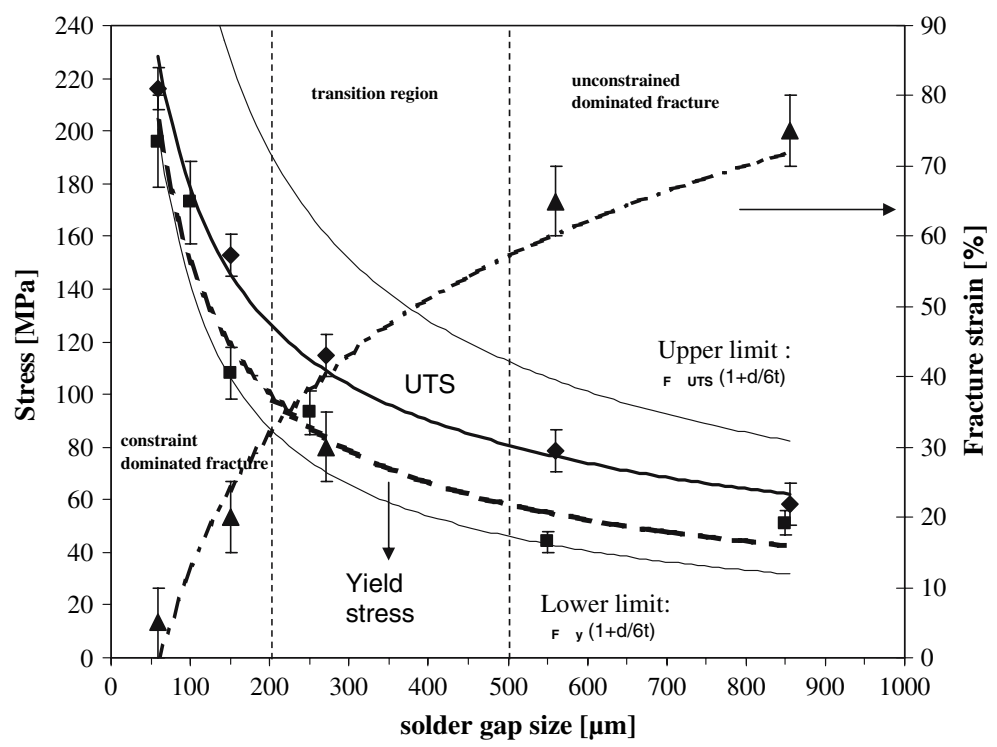

Fig. 4. Experimental ultimate tensile strength (UTS, $\bullet$ ) and fracture strain $(\mathbf{\Delta})$ of $\mathrm{Sn}-3.5 \mathrm{Ag} / \mathrm{Cu}$ joints as a function of thickness. UTS follows a hyperbolic-like behavior as predicted by Orowans approximation for mechanical constrains on brazed joints. The lower and upper limits were calculated according to Ref. 19 with $\sigma_{U T S}=55 \mathrm{MPa}$ and $\sigma_{\mathrm{y}}=48 \mathrm{MPa}{ }^{26}$ The experimental data are lower than the upper limit, because of internal voids and cracks, which act as sites for stress and strain concentration. A similar behavior comparable to this increase of UTS was also determined for the yield stress (घ).

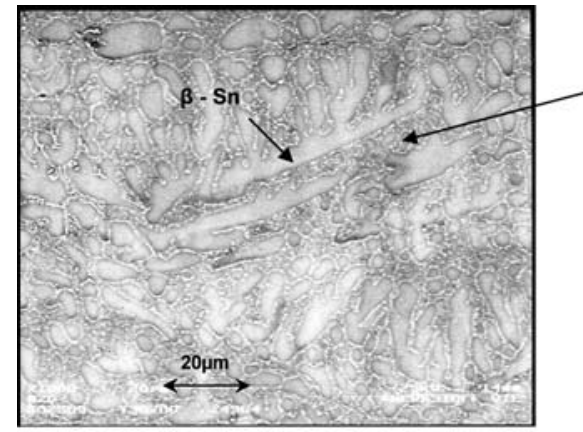

a)

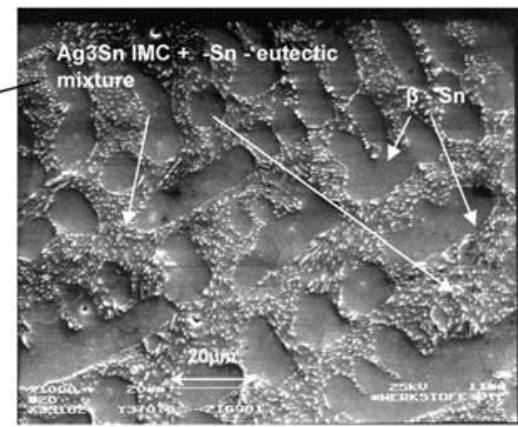

b)

Fig. 5. SEM micrographs of the Ag-Sn eutectic alloy (Sn-3.5Ag) for: (a) gap size $100 \mu \mathrm{m}$ and (b) gap size $500 \mu \mathrm{m}$.

the case of miniaturized joints one can assume that the actual mechanical situation under loading will be dominated by the boundary conditions. Nevertheless, in any complete discussion of the deformation behavior of solder joints, microstructural effects also have to be considered.

A similar behavior as observed for the UTS was found for the yield strength, as shown in Fig. 4. For the very thin joints the differences between the UTS and yield stress are small because of the limited plasticity of thin joints. For thick joints the observed yield stress is dominated by the pure solder value. These results can be understood qualitatively as a consequence of mechanical constraints. Because the elastically deforming base material restricts the solder to deform plastically, one can suggest that not only is the UTS influenced by constraints but that the onset of plastic deformation is also delayed, resulting in higher yield stresses for the entire joint.
The fracture behavior of solder joints with various thicknesses was studied using a tensile stage in the SEM for in situ observation of fracture evolution with increasing stress. Typical examples of these experiments are shown in Figs. 6 and 7, respectively, for a thin joint $(160 \mu \mathrm{m})$ and a thicker one $(790 \mu \mathrm{m})$. It was observed that for thin samples the crack initiation and failure occurs primarily in the region of the IMC/copper and the IMC/solder interface as shown in Fig. 7a. In thicker joints fracture was more pronounced inside the ductile solder (Fig. 7b), therefore a higher ductility can be observed for the entire joint.

Hardness distribution measurements using nanoindentation ${ }^{28}$ on $\mathrm{Sn}-40 \mathrm{~Pb}$ and copper showed that the hardness of the IMC was far higher than that of either the solder or the copper. Because of this material discontinuity, a stress concentration is produced in both the solder/IMC interface and the 


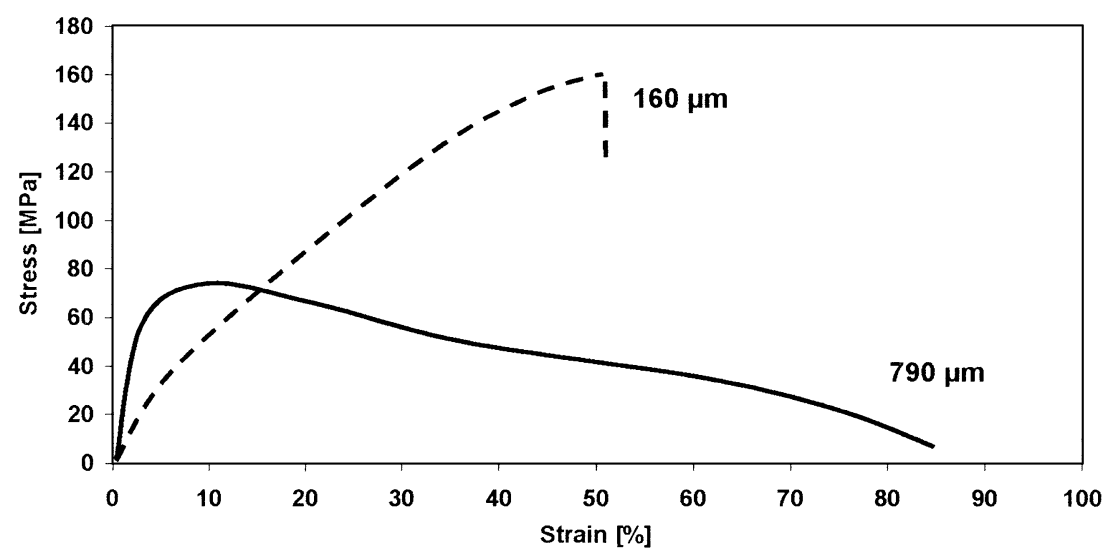

Fig. 6. Stress-strain curves of Sn-3.5Ag solder joints with gap sizes of $160 \mu \mathrm{m}$ and $790 \mu \mathrm{m}$.
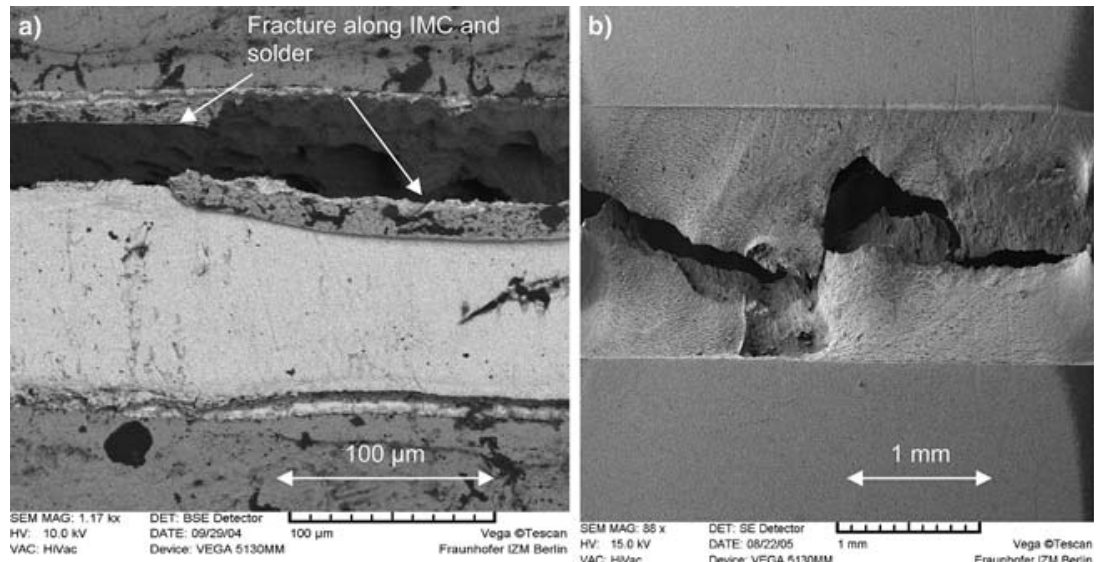

Fig. 7. (a) SEM image of a solder joint with a gap size of $160 \mu \mathrm{m}$ after fracture at $650 \mathrm{~N}$ and strain of $50 \%$ the fracture occurs at the interface between IMC and the solder material. (b) SEM image of a solder joint with a gap size of $790 \mu \mathrm{m}$ after loading at $90 \mathrm{~N}$ and $40 \%$ strain; the fracture occurs inside the solder.

IMC/copper interface when subjected to loading. However, the hardness difference between IMC and solder is larger than between the IMC and copper, and the solder strength is also lower than that of copper. When subjected to loading, the fracture should occur along the IMC/solder interface.

These observations correspond very well with the fracture strain behavior shown in Fig. 4. For thinner gaps the fracture strain is reduced because fracture occurs near the brittle IMC; thicker gaps are more ductile and show higher fracture strains because of fracture development inside the ductile solder. In this case the constraining conditions have less influence on the joint behavior, and fracture can develop as expected in an unconstrained solder joint. Therefore one can give a rough estimation of the regions of constraint-dominated fracture (gap sizes below $200 \mu \mathrm{m}$ ) and non-constraint-dominated fracture (gap sizes larger than $500 \mu \mathrm{m}$ ) with some kind of transition region where fracture occurs near the IMC interface as well as in the solder itself, as depicted in Fig. 4.
Figures 8 and 9 illustrate the stress relaxation behavior of solder joints (normalized to the initial stress level) with gap sizes from $150 \mu \mathrm{m}$ to $750 \mu \mathrm{m}$ at room temperature and at $120^{\circ} \mathrm{C}$ using a relaxation time of only $1 \mathrm{~h}$. For gap sizes of $150 \mu \mathrm{m}$ and $550 \mu \mathrm{m}$ relaxation was carried out for several hours until fracture. The relaxation in the copper was measured at both temperatures and found to be small, therefore it was neglected for the load levels encountered in this study. Following Mavoori et al. ${ }^{28}$ it was not necessary to account for machine compliance because strain rather than cross head displacement was controlled.

Figure 8 shows the normalized stress relaxation for various gap sizes against time at $25^{\circ} \mathrm{C}$. In the case of a $750 \mu \mathrm{m}$ gap size, the stress drop was $30 \%$ in $1 \mathrm{~h}$. On the other hand, for a $150 \mu \mathrm{m}$ gap size, the stress drop was only 5\%, while the stress drop in pure copper was $0.5 \%$. Figure 9 shows the normalized stress relaxation against time at $120^{\circ} \mathrm{C}$, showing that the stress drop is temperature dependent. In the case of a $750 \mu \mathrm{m}$ gap size, the stress drop was 


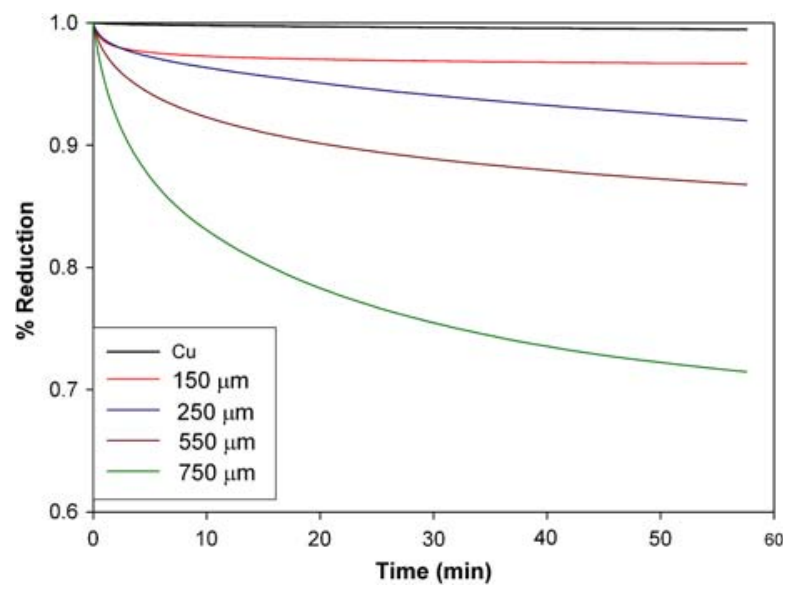

Fig. 8. Percentage stress drop (normalized to the initial stress) of solder joints with varying gap sizes at $25^{\circ} \mathrm{C}$.



Fig. 9. Percentage stress drop (normalized to the initial stress) of solder joints with varying gap sizes at $120^{\circ} \mathrm{C}$.

$45 \%$ in $1 \mathrm{~h}$, while the stress drop for a $150 \mu \mathrm{m}$ gap size was only $10 \%$. The present data indicate that solder joints have constraints imposed that do not allow complete relaxation, which leads to the presence of residual stresses ${ }^{29}$ which particularly in the thin joints may be large enough to cause further damage during service because of the lack of ductility compared to the thick joints. This result can be understood by taking into account the results for the stress-strain behavior of various gap sizes as shown in Figs. 3 and 6. Thick joints show higher ductility than thin joints due to the higher mobility of dislocations and therefore a higher rate of relaxation drop in thick joints is to be expected compared to the highly constrained thin joints.

\section{Shear Experiments}

Preliminary results of shear force-displacement curves until failure of $\mathrm{Sn}-3.5 \mathrm{Ag}$ solder joints as a function of gap size are shown in Fig. 10. A comparison of the normalized maximum shear stress

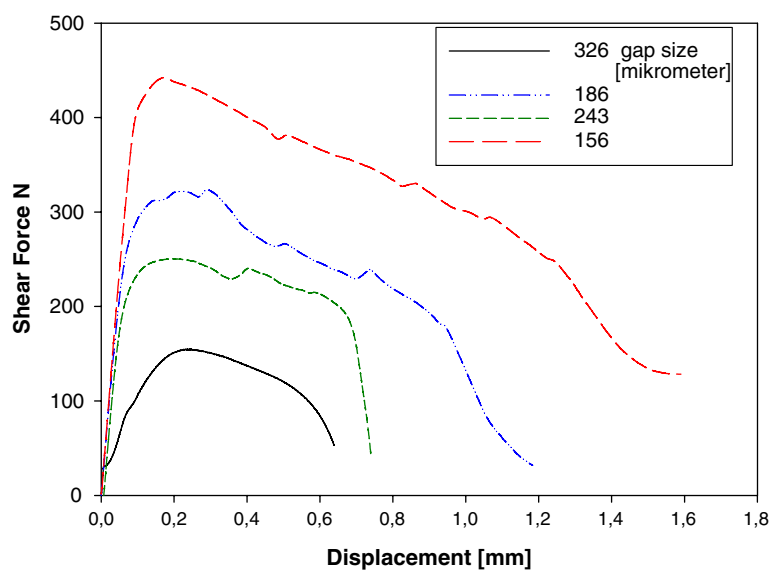

Fig. 10. Shear force-displacement curves until failure of Sn-3.5Ag solder joints for solder joints with various gap sizes.

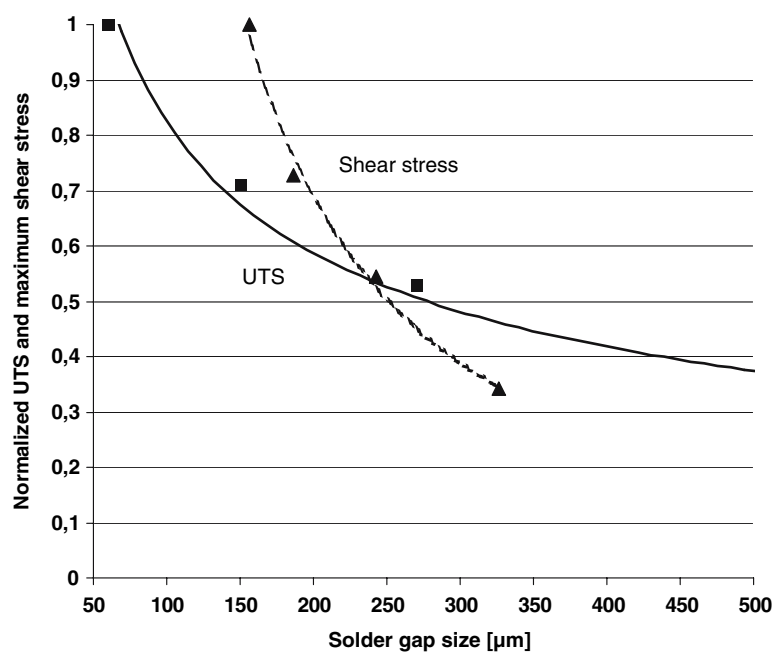

Fig. 11. Comparison of normalized UTS and normalized maximum shear stress of Sn-3.5Ag solder joints. The rate of increase in shear strength in a certain range of joint size $(150-350 \mu \mathrm{m})$ was found to be approximately three times higher than that measured for tensile specimens.

with the normalized UTS is given in Fig. 11. It can be seen, that for gap sizes from $330 \mu \mathrm{m}$ down to $150 \mu \mathrm{m}$ a strong increase of shear strength occurs, which is approximately three times larger than the increase of the UTS (or yield strength) in the same gap-size region. Interpretation of shear results is known to be a difficult task and very few studies have examined the effects of geometry on the elastic and plastic behavior of solder joints tested using the lap-shear technique. ${ }^{8,9}$

The copper substrate will participate in the deformation process during loading, although it is considered relatively thick compared to the solder layer, and will therefore influence the shear behavior of the solder. Shen et al. ${ }^{9}$ pointed out that during shear loading of solder joints the transmission of shear strain into the solder is very ineffective when the solder is in the elastic state. The 
transmission of shear into the solder is effective only when the solder begins to flow plastically and the processes of mechanical constraints are obviously more complex compared to tensile situation. Trends in strength reduction and fractography for Sn-Ag solders on copper substrates were found to be broadly similar for shear and tensile testing modes when taking into account the influence of intermetallic compounds. ${ }^{6}$ However, there appears to be a large variance in the reported overall shear behavior and attention must be paid to comparison of shear results, even for identical solder compositions and substrate combinations. ${ }^{9}$ Further studies of the microstructural features and fracture behavior are needed to clarify these results and are currently under progress.

\section{SUMMARY AND CONCLUSIONS}

Tensile, shear, and stress relaxation tests on Sn-3.5wt.\%Ag solder joints with various gap sizes showed clear evidence of the effect of mechanical constraints. In the case of tensile loading the mechanical constraints result in a strong increase of UTS and yield strength with decreasing gap size and a simultaneous decrease in fracture strain. The observed behavior of the UTS can be explained qualitatively with the well-established theory for brazed joints, first pointed out by Orowan, ${ }^{22}$ owing to the development of three-dimensional stresses in the thinner joints, depending on the diameter and thickness of the soldered joint. Qualitatively, the tensile behavior of solder joints was found to be similar to that of brazed joints, and the influence of the IMC seemed to be of less importance. Additional evidence for the development of dimensional constraints could be found in a significant change of the fracture mode with the joint thickness. Increasing the thickness of the solder gap led to enhanced plastic deformation in the solder volume, which in most cases resulted in fracture inside the solder instead of cracking at the IMC/solder interface. Also for shear loading a clear gap-size-dependent increase of maximum shear stress was observed, but the results indicate a different mechanism for mechanical constraints when compared to tensile tests. The rate of increase in shear strength in a certain range of joint size $(150-350 \mu \mathrm{m})$ was found to be approximately three times higher than that measured for tensile specimens. Stress relaxation tests for various gap sizes showed that solder coupled with a stiff substrate can cause a mechanical constraint that prevents complete relief of stresses in the joint during relaxation, even at elevated temperatures. From the presented results one may conclude that mechanical constraint effects have to be considered very seriously in addition to microstructural effects for reliability issues of miniaturized solder joints in real application. As joint thickness decreases the likelihood of stress relief during the high-temperature dwell, thermome- chanical fatigue might be reduced and residual stress will remain in the solder joint.

\section{ACKNOWLEDGEMENTS}

This research is a contribution to the European COST Action 531. Financial support from the Austrian Science Foundation (FWF) under Project No. P-17346 is gratefully acknowledged. The authors thank D. Vogel and A. Gollhardt of the Institute for Microintegration and Reliability (IZM Berlin) for their support using the SEM for fracture monitoring, data interpretation, and helpful discussions; they also thank Ms. A. Ziering for the preparation of the solder joints.

\section{REFERENCES}

1. W. Plumbridge, R. Matela, and A. Westwater, Structural Integrity and Reliability in Electronics (London: Kluwer Academic, 2003).

2. N. Bonda and I. Noyan, IEEE Trans. Comput. Packag. Manuf. Technol. 19A, 208 (1996).

3. H. Lee, H. Lin, C. Lee, and P. Chen, Mater. Sci. Eng. A 407, 36 (2005).

4. W. Plumbridge, Solder Surf. Mount Technol. 16(2), 13 (2004).

5. H. Lee and M. Chen, Mater. Sci. Eng. A 333, 24 (2002).

6. H. Lee, M. Chen, H. Jao, and T. Liao, Mater. Sci. Eng. A 358, 134 (2003).

7. K. Prakash and T. Sritharan, Mater. Sci. Eng. A 379, 277 (2004).

8. A. Antoniou and A.F. Bastawros, J. Mater. Res. 18(10), 2304 (2003).

9. Y. Shen, N. Chawla, E. Ege, and X. Deng, Acta Mater. 53, 2633 (2005).

10. S.G. Jadhav, T.R. Bieler, K.N. Subramanian, and J.P. Lucas, J. Electron. Mater. 30(9), 1197 (2001).

11. K.N. Subramanian, J. Electron. Mater. 34(10), 1313 (2005).

12. H. Rhee and K.N. Subramanian, J. Electron. Mater. 32(11), 1310 (2003).

13. W. Nix, Met. Trans. A 20, 2217 (1989).

14. E. Arzt, Acta Mater. 46, 5611 (1998).

15. A. Skipor, S. Harren, and J. Botsis, J. Eng. Frac. Mech. 52, 647 (1995).

16. J.P. Ranieri, F.S. Lauten, and D.H. Avery, J. Electron. Mater. 24(10), 1419 (1995).

17. P. Zimprich, A. Betzwar-Kotas, G. Khatibi, B. Weiss, and H. Ipser, Proc. of the 16th European Conference of Fracture (ECF16), ed. E.E. Gdoutos (Springer, 2006), p. 645.

18. J. Cugnoni, J. Botsis, and J. Janczak-Rusch, Adv. Eng. Mater. 8(3), 184 (2006).

19. H. Saxton, A. West, and C. Barrett, Met. Trans. 2, 999 (1971).

20. A. West, H. Saxton, and C. Barrett, Met. Trans. 2, 1009 (1971).

21. H. Saxton, A. West, and C. Barrett, Met. Trans. 2, 1019 (1971).

22. E. Orowan, J. Nye, and W. Cairns, MOS Arm. Res. Dept. Rep. 16, 35 (1945).

23. T. Courtney, Mechanical Behavior of Materials (McGrawHill, 1990), p. 201.

24. D. Vogel, R. Kühnert, M. Dost, and B. Michel, Trans. ASME J. Electron. Packag. 124, 345 (2002).

25. M. Anwander, B. Zagar, B. Weiss, and H. Weiss, Exp. Mech. 1, 40 (2000).

26. B. Weiss, V. Gröger, G. Khatibi, A. Kotas, P. Zimprich, R. Stickler, and B. Zagar, Sens. Actuat. A 99, 172 (2000).

27. M. Abtew and G. Selvaduray, Mater. Sci. Eng. 27, 95 (2000).

28. D. Frear and P. Vianco, Met. Mater. Trans. A 25, 1509 (1994).

29. H. Mavoori, J. Chin, S. Vaynman, B. Moran, L. Keer, and M. Fine, J. Electron. Mater. 26(7), 783 (1997). 